\title{
FEATURES OF LOW-TEMPERATURE STORAGE OF STREPTOMYCES STRAINS - PRODUCERS OF GLYCOSIDAZ INHIBITORS
}

\author{
Anastasia A. Printseva ${ }^{1,2}$ *, Natalya Yu. Sharova ${ }^{1,2}$, Tatyana V. Vybornova ${ }^{1}$, Bairta S. Manzhieva ${ }^{1}$ \\ ${ }^{1}$ All-Russian Research Institute for Food Additives - Branch \\ of V.M. Gorbatov Federal Research Center for Food Systems of RAS, St. Petersburg, Russia \\ ${ }^{2}$ St. Petersburg National Research University of Information Technologies, Mechanics and Optics, St. Petersburg, Russia
}

KEY WORDS:

strain of Streptomyces lucensis

VKPM Ac-1743, strain of Strepto-

myces violaceus VKPM Ac-1734, low-temperature storage, inhibitory activity, proteinase activity

\begin{abstract}
:
The aim of the work is to study the inhibitory activity of the Streptomyces lucensis VKPM Ac-1743 and Streptomyces violaceus VKPM Ac-1734 strains stored at $-18{ }^{\circ} \mathrm{C}$ in a $15 \%$ glycerol solution and in a $0.9 \%$ sodium chloride solution.

The object of the study was the actinomycete strains of S. lucensis VKPM Ac-1743 and S. violaceus VKPM Ac-1734 producers of glycosidase inhibitor, which is a micro-ingredient for creating products with a low glycemic index.

The storage time was nine months. Bookmark storage was performed by flushing with a taped agar starchcontaining environment of Capek. For comparison, we studied the properties of cultures stored at $+4{ }^{\circ} \mathrm{C}$ without cryoprotectant.

Deep cultivation of Streptomyces strains was carried out in a periodic manner on a medium containing corn starch hydrolyzate under the Multitron incubator shaker (INFORS, Switzerland).

Inhibitory activity was determined in inactivated native solutions by a colorimetric method with respect to pancreatic $\alpha$-amylase, a test glycosidase involved in carbohydrate metabolism, and whose activity was chosen as a criterion for assessing the hypoglycemic action of the inhibitor. The proteinase activity of the inactivated native solution was determined by a modified method using a casein substrate.

The experimental data were processed using the methods of mathematical statistics and Excel XP programs.

As a result of the research, it was established that the actinomycete strains of S. lucensis and S. violaceus, the producers of glycosidase inhibitors, can maintain inhibitory activity during low-temperature storage for nine months.

For the $S$. lucensis actinomycete strain, stored in a $15 \%$ glycerol solution at $-18{ }^{\circ} \mathrm{C}$, the maximum inhibitory activity is 48 hours in the biotechnological process and is $(3686 \pm 300) \mathrm{IU} / \mathrm{cm}^{3}$ native solution, and for the $S$. violaceus strain - $(3150 \pm 200) \mathrm{IU} / \mathrm{cm}^{3}$ of the native solution, respectively.

For the strain of actinomycete $S$. lucensis, stored in $0.9 \%$ sodium chloride solution at a temperature of $-18{ }^{\circ} \mathrm{C}$, the maximum inhibitory activity accounts for $72 \mathrm{~h}$ of the biotechnological process and is $(2600 \pm 200) \mathrm{IU} / \mathrm{cm}^{3} \mathrm{of}$ the native solution, and for the strain $S$. violaceus the maximum inhibitory activity accounts for 24 hours of the biotechnological process and is $(3530 \pm 200) \mathrm{IU} / \mathrm{cm}^{3}$ of the native solution.

At a storage temperature of $+4{ }^{\circ} \mathrm{C}$, the inhibitory activity for the strain of actinomycete $S$. lucensis is (560 \pm 20$)$ $\mathrm{IU} / \mathrm{cm}^{3}$ of native solution, and for the strain of $S$. violaceus $-(1747 \pm 100) \mathrm{IU} / \mathrm{cm}^{3}$ of native solution, respectively. On the basis of the data obtained, it can be concluded that a temperature of $-18{ }^{\circ} \mathrm{C}$ is preferred for long-term

Storage. $0,002) \mathrm{U} / \mathrm{cm}^{3}$

The obtained data can be applied in further studies to develop conditions for long-term storage of collection crops.
\end{abstract}

\section{Introduction}

Keeping strains in working condition and their valuable properties are important working conditions with microorganisms - from the initial study to their use in the production of various microingredients and biological products.

The study of the biosynthetic activity of Streptomyces strains - producers of glycosidase inhibitors in the process of long-term low-temperature storage is an important trend and makes a significant theoretical and practical contribution to the problem of the preservation of increasing biological diversity.

Methods for storing microorganisms include periodic subcultures on fresh agar media, storage under a layer of mineral oil, in distilled water and physiological saline, drying on solid carriers (soil, sand, paper, resins, gelatin, active carbon, cereal grains, and many others) and at low temperatures $[1,2,3]$.

The method of periodic transfers is used for many microorganisms, as it is simple to perform. But the method has drawbacks: the need to comply with the rules of reseeding, the need for a large number of dishes and nutrient media, a significant investment of time, the risk of contamination of the culture, errors in labeling strains, etc. There are cases of changes in the biological properties of microbial cultures and even their death. When frequent transfers are carried out, producer strains due to spontaneous dissociation can often lose or reduce the ability to produce target products.

Long-term storage of cells, without loss of valuable properties, is carried out by freezing the microorganisms or drying them from the frozen state (lyophilization), or directly from the liquid state (L-drying). The high effect of conservation by these methods is achieved by the fact that the cells, being deprived of free water in conditions of sub-zero and (or) cryogenic temperatures, pass into a state of anabiosis [4].

In order to reduce the impact of many damaging factors in the process of freezing biological structures experimentally, so-called protective substances, or cryoprotectants, were selected. Two types of cryoprotectors are used in the storage of bacteria. The first type includes glycerin and dimethyl sulfoxide, which easily pass through the cell membrane and provide both intracellular and extracellular protection against freezing. The second type of cryoprotectants includes substances such as sucrose, lactose, glucose, lures, sorbitol, dextran, polyvinylpyrrolidone and polyglycol. They provide a protective effect on the outer surface of the cell membrane. Glycerol and dimethyl sulfoxide proved to be more effective than cryoprotectants of the second type, and suitable for a wide range of bacteria. Glycerin is successfully used to freeze various microorganisms (Serratia marcescens, Erwinia aroideae, Claviceps sp., Acremorium chrysogenum, S. cerevisiae, C. utilis, 
and many others), while achieving a high percentage of survival while maintaining the properties [3].

Analysis of the literature suggests that the rapid heating of frozen microorganisms leads to their rapid recovery $[1,5]$. Similar tests were conducted with frozen bacterial cells from the American Type Culture Collection [1,6]. To revive frozen cultures, they are quickly thawed in a water bath at $37^{\circ} \mathrm{C}$ and shaken gently until all the ice has melted.

Streptomycetes is a genus of bacteria of the family Streptomycetaceae of the order Actinomycetales, which includes bacteria that tend to form branching hyphae that can develop into mycelium. In the genus Streptomyces, the filaments of the mycelium do not break up into fragments and can form an abundant aerial mycelium with long chains of spores [7].

The collection of microorganisms of the All-Russian Research Institute of Food Additives (VNIIPD) contains the Streptomyces lucensis VKPM Ac-1743 and Streptomyces violaceus VKPM Ac-1734 strains - producers of glycosidase inhibitors, which are biologically active substances and potential food micro-ingredients [8]. Earlier studies have shown that during short-term storage for 30 days at a low temperature of $12{ }^{\circ} \mathrm{C}$, the strains retained their viability and inhibitory activity [9].

The aim of the work is to study the inhibitory activity of Streptomyces lucensis VKPM Ac-1743 and Streptomyces violaceus VKPM Ac-1734 strains stored at $-18{ }^{\circ} \mathrm{C}$ in a $15 \%$ glycerol solution and in a $0.9 \%$ sodium chloride solution for 9 months.

\section{Materials and methods}

The object of the research was the strains of $S$. lucensis VKPM Ac-1743 and S. violaceus VKPM Ac-1734 [10,11], selected in VNIIPD and deposited in the All-Russian Collection of Industrial Microorganisms.

Strains of Streptomyces were stored at $-18{ }^{\circ} \mathrm{C}$ for nine months. Bookmark storage was performed by flushing with a taped agar starch-containing environment of Capek.

Cultures of $S$. lucensis and S. violaceus were stored in $15 \%$ glycerol solution and in $0.9 \%$ sodium chloride solution (saline).

For comparison, we studied the properties of cultures stored at $+4{ }^{\circ} \mathrm{C}$ without cryoprotectant.

Depth cultivation of Streptomyces strains was carried out in a periodic manner on a medium containing corn starch hydrolyzate under Multitron incubator shaker (INFORS, Switzerland) in 750 $\mathrm{cm}^{3}$ flasks at a temperature of $+(29 \pm 1){ }^{\circ} \mathrm{C}$ with a stirring speed $(160 \pm 20)$ revolutions per minute for 96 hours $[10,11]$.

The composition of the medium for fermentation $\left(\mathrm{g} / \mathrm{dm}^{3}\right)$ : starch hydrolyzate with DE dextrose equivalent $=(25 \pm 5) \%-$ 20 ; soy flour $-5,0$; sodium chloride $-3,0$; potassium phosphate dibasic - 1,0; magnesium sulphate semi-sodium - 0,5; pH 7,0 [12].

The recovery process of frozen cells was carried out by rapid thawing at a temperature of $+37^{\circ} \mathrm{C}$ for 3 minutes.

Inhibitory activity was determined in inactivated native solutions by a colorimetric method with respect to pancreatic $\alpha$-amylase (test-enzyme, «Sigma», USA) [13]. Before determination, inactivation of native amylase in a native solution was carried out by heat treatment at $+(98 \pm 1){ }^{\circ} \mathrm{C}$. The proteinase activity of the inactivated native solution was determined by a modified method using casein substrate [14].

The experimental data were processed using the methods of mathematical statistics and Excel XP programs.

\section{Results and discussion}

Actinomycetes of the Streptomyces genus possess active enzyme systems and are capable of producing such hydrolytic enzymes as amylases, proteases, etc. A distinctive feature of actinomycetes is the ability to synthesize enzyme inhibitors. The investigated strains of $S$. lucensis and $S$. violaceus are producers of the glycosidase inhibitor, therefore their biosynthetic ability during storage was evaluated by the indicator "inhibitory activity".

The results showed that the degree of inhibition of pancreatic $\alpha$-amylase in the studied strains stored in $15 \%$ glycerol solution and $0,9 \%$ sodium chloride solution ranged from $10 \%$ to $55 \%$, which corresponds to the value of bookmarks for storage.

After prolonged exposure to low temperatures on the strains of $S$. lucensis and $S$. violaceus during nine months of storage, it was found that inhibitory activity remained at a higher level at lower storage temperatures than at a positive temperature of $+4{ }^{\circ} \mathrm{C}$ (Figure 1 and Figure 2).

Figure 1 shows a graph of the inhibitory activity of the strain S. lucensis, which was stored at temperatures of $+4{ }^{\circ} \mathrm{C}$ and $18{ }^{\circ} \mathrm{C}$, on the duration of cultivation on a starch-containing medium.

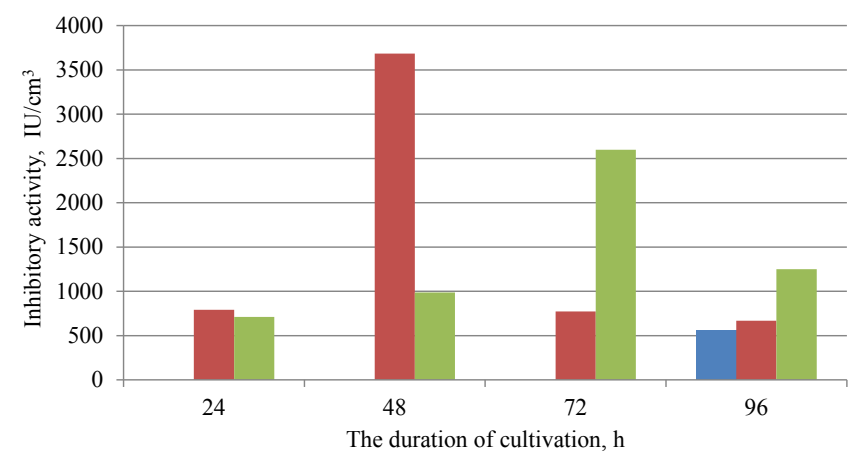

in storage at $+4{ }^{\circ} \mathrm{C}$

varage at $-18{ }^{\circ} \mathrm{C}$ in $15 \%$ glycerol solution

w storage at $-18{ }^{\circ} \mathrm{C}$ in $0,9 \%$ sodium chloride solution

Figure 1 . The dependence of the inhibitory activity of the strain S. lucensis on the duration of cultivation on a starch-containing medium

The maximum inhibitory activity for the strain of actinomycete $\mathrm{S}$. lucensis stored in a $15 \%$ glycerol solution at a temperature of $-18{ }^{\circ} \mathrm{C}$ is 48 hours in the biotechnological process and is $(3686 \pm 300) \mathrm{IU} / \mathrm{cm}^{3}$ of the native solution. When stored in a $0.9 \%$ sodium chloride solution, the maximum inhibitory activity accounts for 72 hours of the biotechnological process and amounts to $(2600 \pm 200) \mathrm{IU} / \mathrm{cm}^{3}$ of the native solution.

At a storage temperature of $+4{ }^{\circ} \mathrm{C}$, the inhibitory activity for the strain of actinomycete $S$. lucensis is $(560 \pm 20) \mathrm{IU} / \mathrm{cm}^{3}$ of the native solution.

Figure 2 shows a graph of the inhibitory activity of the $S$. violaceus strain stored at temperatures of $+4{ }^{\circ} \mathrm{C}$ and $-18{ }^{\circ} \mathrm{C}$, on the duration of cultivation on a starch-containing medium.

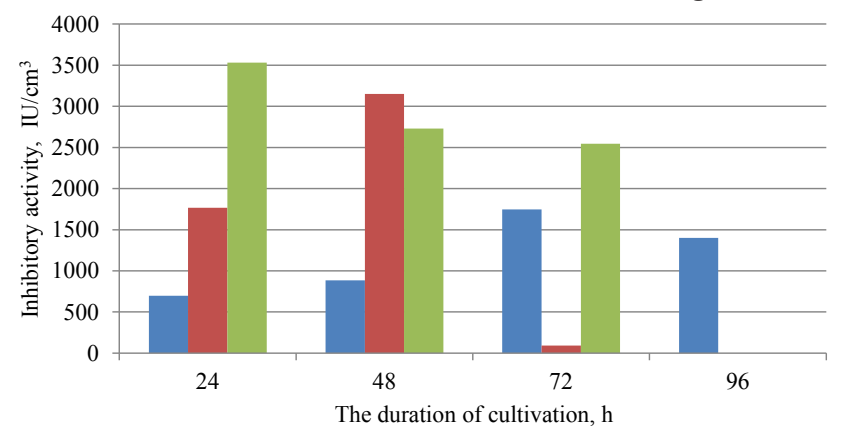

a storage at $+4^{\circ} \mathrm{C}$

m storage at $-18{ }^{\circ} \mathrm{C}$ in $15 \%$ glycerol solution

astorage at $-18^{\circ} \mathrm{C}$ in $0,9 \%$ sodium chloride solution

Figure 2. Dependence of the inhibitory activity of S. violaceus strain on the duration of cultivation on a starch-containing medium 
For the strain of actinomycete $S$. violaceus, stored in a $15 \%$ glycerol solution at a temperature of $-18{ }^{\circ} \mathrm{C}$, the maximum inhibitory activity falls on $48 \mathrm{~h}$ of the biotechnological process and is $(3150 \pm 200) \mathrm{IU} / \mathrm{cm}^{3}$ of the native solution. When stored in a $0.9 \%$ sodium chloride solution, the maximum inhibitory activity accounts for 24 hours of the biotechnological process and is $(3530 \pm 200) \mathrm{IU} / \mathrm{cm}^{3}$ of the native solution.

At a storage temperature of $+4{ }^{\circ} \mathrm{C}$, the inhibitory activity for the strain of actinomycete $S$. lucensis is $(560 \pm 20) \mathrm{IU} / \mathrm{cm}^{3}$ of native solution, and for the strain of $S$. violaceus - (1747 \pm 100$)$ $\mathrm{IU} / \mathrm{cm}^{3}$ of native solution, respectively.

On the basis of the data obtained, it can be concluded that a temperature of $-18{ }^{\circ} \mathrm{C}$ is preferred for long-term storage.

With a sharper temperature drop (from $-18{ }^{\circ} \mathrm{C}$ to $+37^{\circ} \mathrm{C}$ ), the restoration of biochemical reactions in response to stress is intensified.

As a result of the addition of glycerol to the medium, the concentration of electrolytes decreases after reaching an equilibrium state with ice at any temperature. Glycerin prevents the increase in salt concentration to a level that causes a violation of biochemical processes in the cells of microorganisms during freezing.

Since the main criterion for assessing the vital activity and biosynthetic ability of microorganisms is the activity of their enzyme system, the effect of temperature on the protease activity of streptomycetes strains was studied.
During the cultivation of Streptomyces strains, proteinase activity ranged from $(0,012 \pm 0,001) \mathrm{U} / \mathrm{cm}^{3}$ to $(0,072 \pm 0,002)$ $\mathrm{U} / \mathrm{cm}^{3}$. As a result of their storage in a glycerin solution at a temperature of $-18{ }^{\circ} \mathrm{C}$, the detected proteinase activity was $1,2-1,3$ times higher than the protease activity of the cultures after storage at $+4{ }^{\circ} \mathrm{C}$. Storing the strains in saline solution adversely affected proteinase activity, namely, the index decreased by $2-2,2$ times. It is possible that the strains exhibit an inhibitory effect not only with respect to amylases, but also to proteolytic enzymes.

Thus, the investigated strains of S. lucensis VKPM Ac-1743 and S. violaceus VKPM Ac- 1734 retained high biosynthetic activity at a temperature of $-18^{\circ} \mathrm{C}$ and stored for nine months.

\section{Conclucion}

The investigated strains of streptomycetes retain biosynthetic activity at low temperature for nine months. For long-term storage, a temperature of $-18{ }^{\circ} \mathrm{C}$ is more preferable than a positive temperature. The protective effect of the cell structure of the strains is largely provided by glycerin. The activation of the enzyme system of streptomycetes is intensified with a sharper temperature difference. Further study of the effect of low temperatures on the properties of streptomycetes producers of amylolytic enzyme inhibitors is of interest and in the long term makes it possible to adjust the conditions for longterm storage of collection cultures.

\section{REFERENCES}

1. Pokhilenko, V.D., Baranov, A.M., Detushev, K.V. (2009). Methods of long-term storage of collection cultures of microorganisms and development trends. Proceedings of higher educational institutions. Volga region. Medical Sciences, 4 (12), 99-121. (in Russian)

2. Savkina, O.A., Ternovskoi, G.V., Lokachuk, M.N., Pavlovskaya, E.N., Safronova, V.I. (2014). Cryopreservation to be a progressive method for keeping up valuable strains of lactic acid bacteria and yeasts. Agricultural Biology, 49(4), 112-119. (in Russian)

3. Uzunova-Doneva, T., Donev, T. (2005). Anabiosis and conservation of microorganisms. Journal of Culture Collections, 4, 17-28.

4. Safronova, V.I., Tikhonovich, I.A. (2012). Authorized long-term depositation of agricultural microorganisms in the departmental collection of the russian academy of agricultural sciences. Agricultural Biology, 47(3), 32-36. (in Russian)

5. Malik, K.A., Claus, D. (1987). Bacterial culture collection: Their importance to biotechnology and microbiology. Biotechnology and Genetic Engineering Reviews, 5(1), 137-197. DOI: 10.1080/02648725. 1987.10647837

6. Hern, R. (1983). Storage of microorganisms. Methods of general bacteriology, 512-534.

7. Lysak V.V. (2007). Microbiology. Minsk: BSU.-426 p. ISBN 985-485-7093. (In Russian)

8. Sharova, N. Yu. (2015). Amylase inhibitors from Streptomyces lucensis VKPM Ac-1743 and Streptomyces violaceus VKPM Ac-1734. Applied Biochemistry and Microbiology, 58(1), 58-63. DOI: 10.1134/ S0003683815010159
9. Sharova N.Yu., Vybornova T.V., Printseva A.A., Manzhieva B.S. (2018). The properties of the conidia of strains of the actinomycete Streptomyces lucensis and Streptomyces violaceus during storage at low temperatures. Food systems,1(3), 27-32. DOI: 10.21323/26189771-2018-1-3-27-32. (In Russian)

10. Patent No. 2346042. The actinomycetes strain Streptomyces violaceus producer inhibitor field of glycosidase inhibition / Sharova N. Yu., Nikiforova T. A., Pozdnyakova T. A. Publ. 10.02.2009, bul. No. 4. (in Russian)

11. Patent No. 2355755. The actinomycetes strain Streptomyces lucensis producer inhibitor field of glycosidase inhibition / Sharova N. Yu. Pozdnyakova T. A., Chodkiewicz O. A. Publ. 20.05.2009, Byul. No. 14 (in Russian)

12. Khodkevich, O.A. (2009). Development of a technology for the biosynthesis of an $\alpha$-glycosidase inhibitor by actinomycetes of the genus Streptomyces and the use of a complex additive based on it in breadmaking. Author's abstract of the dissertation for the scientific degree of Candidate of Technical Sciences. St.Petersburg, St.Petersburg State University of Low-Temperature and Food Technologies, 16 p. (in Russian)

13. Akulova, N.Yu. (1993). Streptomyces $\alpha$-glucosidase inhibitors. Allocation and properties. Author's abstract of the dissertation for the scientific degree of Candidate of Biological Sciences. St. Petersburg, St-Petersburg Chemical- Pharmaceutical Institute, 22 p. (in Russian)

14. Rukhlyadeva A.P., Polygalina G.V. (1981). Methods for determining the activity of hydrolytic enzymes. M: Legkaya i pishchevaya promyshlennost'.-288 p. (in Russian)

\section{AUTHOR INFORMATION}

Anastasia A. Printseva - junior research scientist, All-Russian Research Institute for Food Additives - Branch of V.M. Gorbatov Federal Research Center for Food Systems of RAS, ITMO University. 191014, St. Petersburg, Liteyny prospect, 55. Tel.: +7-962-703-61-67. E-mail: djkr_yfcnz@mail.ru. "corresponding author

Natalya Yu. Sharova - doctor of technical sciences, professor of the Russian Academy of Sciences, All-Russian Research Institute for Food Additives - Branch of V.M. Gorbatov Federal Research Center for Food Systems of RAS, ITMO University. 191014, St. Petersburg, Liteyny prospect, 55. Tel.: +7-900-624-11-09.E-mail: natalya_sharova1@mail.ru

Tatyana V. Vybornova - research scientist, All-Russian Research Institute for Food Additives - Branch of V.M. Gorbatov Federal Research Center for Food Systems of RAS. 191014, St. Petersburg, Liteyny prospect, 55. Tel.: +7-911-221-57-15. E-mail: vniipakk@mail.ru

Bairta S. Manzhieva - junior research scientist, All-Russian Research Institute for Food Additives - Branch of V.M. Gorbatov Federal Research Center for Food Systems of RAS. 191014, St. Petersburg, Liteyny prospect, 55. Tel.: +7-950-042-15-44. E-mail: bmanzhieva@gmail.com Authors are equally relevant to the writing of the manuscript, and equally responsible for plagiarism

The authors declare no conflict of interest 